REVISTA X, Curitiba, volume 14, n.6,p. 272-285, 2019.

\title{
LEITURA E ESCRITA NOS ANOS INICIAIS: O COMPROMISSO COM A FORMAÇÃO PARA ALÉM DO CONFORMISMO E DA ADAPTAÇÃO
}

\author{
Reading And Writing In Elementary School: Commitment To Teaching Beyond \\ Conformism And Adaptation
}

\author{
Maíra de Sousa EMERICK DE MARIA (UFSC) ${ }^{1}$
}

\begin{abstract}
RESUMO: o presente artigo apresenta uma discussão que retoma as práticas de leitura e de escrita na escola, em especial, nos anos iniciais do Ensino Fundamental. Para tanto, traz um recorte de uma das formações realizadas pelo Programa Federal Pacto Nacional pela Alfabetização na Idade Certa (PNAIC/SC), no ano de 2018. Nessa formação, o tema foi planejamento docente, e, a partir dele, foi proposto uma articulação entre o trabalho com leitura, escrita e análise linguística nos anos iniciais. Essa discussão tem como base a proposta do ensino do sistema de escrita alfabética intrinsicamente relacionado aos usos sociais da escrita pelos sujeitos nos diferentes contextos com vistas a uma formação emancipadora. Os autores base são: Britto (2003; 2012), Geraldi (1984; 1991) e Libâneo (1990). Assim, o objetivo do trabalho é problematizar as ações com o texto na sala de aula e algumas práticas cristalizadas na escola. Para isso, fez-se uma seleção de atividades que envolvem a escrita e que foram realizadas com uma turma de terceiro ano do Ensino Fundamental numa escola pública de São José/SC.
\end{abstract}

PALAVRAS-CHAVE: Leitura; Escrita; Alfabetização; Formação; Emancipação.

\begin{abstract}
This paper presents a discussion that revisits reading and writing activities in schools, especially from the Year 1 to the Year 5 of Elementary School. In order to revisit this topic, this study has as its scope the in-service teacher education course held by the Brazilian Federal Program National Pact for Literacy at the Right Age (NPLRA/SC, or PNAIC/SC in Portuguese), in the year of 2018. The topic of the above-mentioned course was teaching planning, and within this topic an articulation among the activities of reading, writing and linguistic analysis was proposed to be applied for Elementary School Years. This articulation was informed by the proposal for teaching the alphabetic writing system intrinsically related to the social uses of writing by subjects in different contexts aiming for an emancipatory education. The base authors are: Britto (2003; 2012), Geraldi (1984; 1991) and Libâneo (1990). To this end, the objective of the work is to problematize the uses of texts in the classroom and some crystallized teaching practices at school. To reach this objective, a selection of activities involving writing were carried out in a Year 3 class of an elementary public school in São José/SC.
\end{abstract}

${ }^{1}$ Doutoranda do Programa de Pós-graduação em Linguística da Universidade Federal de Santa Catarina. 
REVISTA X, Curitiba, volume 14, n.6,p. 272-285, 2019.

KEYWORDS: Reading; Writing; Literacy; Continuing Teacher Education; Emancipation.

\section{INTRODUÇÃO}

É bastante recorrente em processos formativos iniciais e continuados de alfabetizadores tanto quanto em suas práticas docentes certa equiparação entre a alfabetização em si e a escolha metodológica, pois, como discorre Mortatti (2000), a história da alfabetização no Brasil está atrelada à trajetória dos métodos. Segundo a autora, em seus estudos do percurso histórico da alfabetização, correspondentes aos anos de 1876 a 1994, houve uma prevalência de disputas entre métodos sintéticos e analíticos. Esses métodos ora privilegiavam partes das palavras, com ensino isolado das letras ou das famílias silábicas, por exemplo, ora privilegiavam a palavração para depois a composição de pequenas sentenças (Cf. FRANCO, 1997). Mortatti ainda trata da forte influência dos estudos de base piagetiana nas salas de aula brasileiras. Estes estudos ganharam força no Brasil por influência do construtivismo de Emília Ferreiro, que, apesar de não ser apresentado como metodologia, foi aplicado como tal. Nesse sentido, “[...] para a prática da alfabetização, tinha-se, anteriormente, um método, e nenhuma teoria; com a mudança de concepção sobre o processo de aprendizagem da língua escrita, passou-se a ter uma teoria, e nenhum método”. (SOARES, 2004, p. 11)

Parece, portanto, que os alfabetizadores, em alguma medida, ao aprofundarem os constructos teóricos da sua área, afastaram-se das questões metodológicas, marcando assim uma dicotomia entre teoria e prática. Ocorre, nesse sentido, um descolamento entre as concepções que fundamentam a educação das práticas em sala de aula. No entanto, apesar dessa recorrente dicotomia, é importante compreender que o docente necessita dos conhecimentos teóricos para elaborar seu planejamento e prever suas ações para não propor o impossível, tampouco aquilo que não faz sentido para o percurso formativo do estudante (Cf. LIBÂNEO, 1990).

Nesse sentido, é condição para o agir docente a compreensão das bases filosóficas e teóricas (o que inclui as concepções e correntes pedagógicas) que subsidiam as suas escolhas metodológicas. Não é foco deste artigo discorrer sobre essas bases, porque isso demandaria um estudo mais aprofundado, mas é importante marcar que o apagamento das discussões sobre as concepções de conhecimento, objeto de ensino, alfabetização, aprendizagem, entre outras, em favor de discussões apenas 
REVISTA X, Curitiba, volume 14, n.6,p. 272-285, 2019.

práticas pode gerar falta de clareza quanto ao papel da escola e do professor no processo formativo dos sujeitos.

Por conta desse contexto, programas de formação continuada são necessários. Justamente pela compreensão que a formação docente é um processo continuum, haja visto que mesmo após realizar cursos de graduação e pós-graduação e ter anos de experiência em sala de aula, os sujeitos não estão prontos e se desenvolvem à medida que aprendem e, ao se desenvolverem, se instrumentalizam para refletirem sobre sua prática.

No hall de cursos oferecidos aos professores, apresento, em linhas gerais, o Pacto Nacional pela Alfabetização na Idade Certa (PNAIC), que teve início em 2012 e foi implementado por meio de políticas públicas do Governo Federal em parceria com os estados e municípios. Numa visão geral, o referido programa de formação contou com extensivos encontros de estudos voltados, inicialmente, a professores dos Anos Iniciais e depois ampliado para professores da Educação Infantil e também para gestores.

O objetivo do PNAIC, portanto, era assegurar que todas as crianças se alfabetizassem até os oito anos de idade, ao final do terceiro ano do Ensino Fundamental, e, para isso, os profissionais responsáveis por esse processo foram formados para adensar sua compreensão sobre as especificidades da alfabetização.

Entre os anos de 2015 e 2018, fui uma das formadoras do Programa no estado de Santa Catarina, por isso meu interesse sobre os processos formativos de professores no que tange à alfabetização. Em um dos encontros, no início de 2018, o foco foi o planejamento docente, documento fundamental para qualquer trabalho em sala de aula. Junto a essa discussão, com o intuito de tratar das questões mais específicas referentes à língua, o encontro - com 16 horas de estudo - foi organizado para debater sobre a entrada dos textos em sala de aula e como os professores poderiam planejar as atividades envolvendo esses textos.

Para isso, além de alinhar a concepção de planejamento, afastando-se da compreensão de que este é um documento meramente administrativo, e aproximando-se da importância pedagógica desse instrumento, foi refletido sobre como se dá o ensino do sistema de escrita alfabética (SEA) em favor dos seus usos sociais. Assim, não faz sentido realizar atividades descoladas da prática social, que tratam a língua apenas como um conjunto de regras isoladas de seu uso. 
REVISTA X, Curitiba, volume 14, n.6, p. 272-285, 2019.

Neste artigo, portanto, proponho uma breve discussão a partir do panorama apresentado acima sobre os contornos do trabalho realizado em sala com os textos escritos nos Anos Iniciais. Para isso, dividi o texto em outras duas seções: a primeira com um aporte teórico que retoma algumas discussões da área de Educação Linguística, em especial, sobre leitura, escrita e análise linguística; e a segunda com uma análise de atividades realizadas por um aluno do terceiro ano do Ensino Fundamental de uma escola pública do município de São José/SC. Por fim, finalizo propondo algumas reflexões que visam colaborar com as discussões referentes à docência e ao ensino de linguagem.

\section{OS CONSENSOS SOBRE O ENSINO DE LEITURA E DE ESCRITA: LEITOR E PRODUTOR DE TEXTOS APENAS NA/PARA ESCOLA?}

Parece acordado socialmente que a leitura é importante para a formação dos sujeitos. Assim como afirma Britto (2012), na cultura ocidental contemporânea, ler é um valor. Por isso, não são raras as propagandas de projetos e ações que incentivam à leitura, em geral, atrelando o ato de ler ao prazer e à fruição. No entanto, esta concepção de leitura está bastante vinculada a uma visão utilitarista do senso comum, referente à habilidade de ler no dia a dia, a exemplo de listas de mercado, bulas de remédio etc., bem como uma visão romantizada acerca do prazer proporcionado pela leitura, que está associada à criatividade, imaginação e passatempo.

Em seu sentido lato, leitura pode ser usada para representar muitas ações, como leitura de mundo, leitura de imagem, leitura de mãos, por exemplo, no entanto, o sentido que trago neste artigo e que é caro à escola diz respeito à leitura de artefatos escritos, o que exige, necessariamente, a apropriação do sistema de escrita alfabética. Entretanto, para além da sua apropriação para decodificar/decifrar o material escrito, também é fundamental a compreensão mais aprofundada do que foi lido, num encontro entre leitor e autor por meio do texto, que envolve processos intersubetivos e intrasubjetivos.

Nesse sentido, a leitura é compreendida como "[...] uma atividade intelectual muito particular, que exige, mais que em outras atividades intelectuais, que a pessoa se ponha inteira de corpo e mente na ação; exige do leitor autocontrole, domínio de si, de sua atenção, de seus olhos, de seu corpo e de suas ideias" (BRITTO, 2018, p. 18). É, pois, uma atividade que precisa ser ensinada. 
REVISTA X, Curitiba, volume 14, n.6,p. 272-285, 2019.

Desse modo, a escola, em especial nos anos iniciais do Ensino Fundamental, é responsável pelo ensino do SEA nos/pelos usos sociais a fim de possibilitar que os alunos realizem atividades com os textos escritos, tanto no âmbito da leitura quanto no âmbito da produção, bem como possam refletir sobre a língua que usam por meio da análise linguística. Isto é, não é suficiente o ensino instrumental da leitura para simplesmente atender as demandas do capital e formar trabalhadores alienados de seu papel social.

A percepção genérica de ler como um bem em si, desvinculado das formas de ser na sociedade e da formação cultural, ignora qualquer indagação mais forte de cultura, conhecimento, educação e política. E, na lógica da razão instrumental, é preciso que seja assim para que haja coincidência entre concepção de leitura e a também vaga noção de participação social: o leitor crítico seria crítico porque, informado pelos meios de comunicação de massa e outros formadores de opinião, mantém-se na lógica liberal da quase democracia própria do capitalismo contemporâneo. (BRITTO, 2012, p. 37)

Em consonância com as críticas feitas por Britto (2012), compreendo, então, que o trabalho com os textos na escola não pode ser artificial, como um mero exercício de decodificação, treino ou cópia apartado de reflexão. Por isso, as atividades que envolvem a leitura e a escrita devem tratar o texto na sua materialidade social, o que exige a apresentação do texto próximo de sua produção real, considerando o gênero, contexto de produção, autoria, objetivos etc. e, principalmente, analisando os discursos apresentados, que não são isentos, mas sim carregados de ideologia.

Essa discussão retoma o que foi apontado no título da seção e corrobora com o entendimento do papel da escola na sociedade. Em vista disso, não se forma leitores e produtores de texto somente para escola, capazes de localizar as informações no texto e de reproduzir o que já foi dito, e sim, sujeitos que lidem com texto de forma autônoma e consciente. Sujeitos que possam escolher e tomar decisões, que apreciem a arte, se apropriem do conhecimento científico das diferentes áreas e questionem sua condição humana.

Portanto, assumisse que há diferenças entre ler uma bula de remédio, uma notícia (leituras cotidianas) e uma obra literária (leitura que transcende o tempo e o espaço), por exemplo, porque se vai a esses textos com objetivos muito distintos, do mesmo modo se agenciam conhecimentos distintos para compreendê-los. Por isso, a importância de apresentar os textos em sua materialidade em sala de aula e compreender os objetivos da leitura, como aponta Britto (2012): 
Lê-se para deleite pessoal, fruição, entretenimento, como quando se pega um livro ou uma revista e deixa-se que o pensamento flua sem compromisso ou objetivo além do prazer de ser e de experimentar situações, ambientes, acontecimentos. Lê-se igualmente para buscar informação do que ocorre na política, na economia, na ordem social, como quando se faz a leitura frequente de jornais e periódicos; lê-se, ainda, para instruir-se sobre coisas práticas ou interessantes ou em busca de ampliação de conhecimento, seja sobre história, ciência, cultura; e pode-se, também, ler como forma de autoconhecimento ou aprimoramento pessoal. (BRITTO, 2012, p. 46-47)

Por isso, é papel da escola a formação do leitor, apresentando e ampliando práticas com a leitura que transcendam a imediatez do cotidiano e que possibilitem maior atuação e intervenção desses sujeitos na sociedade.

Concomitante ao trabalho com a leitura, está o trabalho com a produção textual. A atividade de escrever textos se faz presente na rotina escolar, exemplo disso é que as crianças, ao final de um ano letivo, levam seus cadernos com inúmeras escritas para casa. Todavia, historicamente e ainda hoje, são comuns os exercícios de cópias, de preenchimento de lacunas, reescrita de listas, o que, em geral, não exigi um processo de reflexão do aluno sobre sua escrita, tampouco o possibilita ocupar o lugar de autor.

E mesmo quando o foco é uma escrita autoral, o texto ainda está assentado em fórmulas prontas, sob a forma da chamada redação escolar. Comumente, a redação é escrita com base em um determinado tema definido previamente pelo docente, o qual objetiva avaliar o aluno. Esse tipo de atividade é bastante problemático pois torna o texto uma coisa, um produto fechado, assim como aponta Britto (2003):

\begin{abstract}
Absolutização do texto/redação como coisa, isto é, sem motivação e sem sujeitos, a redação passa de substantivo abstrato (o ato de redigir) a substantivo concreto (o uma redação; Joguei fora a redação de ontem). Seu único fim é a correção (e, por isso, pode mesmo ser jogada fora depois que o professor deu a nota). É interessante anotar que a palavra texto ficou reservada nesta história para aquilo que se encontra nos livros: o aluno lê textos e faz redações. (BRITTO, 2003, p. 50)
\end{abstract}

Diferentemente da redação, a produção textual, bastante debatida por Wanderlei Geraldi, como nas obras O texto na sala de aula (1984) e Portos de passagem, objetiva possibilitar ao aluno esse lugar de locutor do seu próprio discurso, que será produzido a partir de orientações do docente, mas sem receita pronta para isso. Assim, o aluno pensará no que vai dizer, para quem vai dizer, por que vai dizer desse modo e como agenciará os recursos linguísticos para que seu projeto de texto seja atingido. (Cf. GERALDI, 1991) 
REVISTA X, Curitiba, volume 14, n.6,p. 272-285, 2019.

Nessas condições, então, o professor não é mero corretor que aponta os "erros" referentes à norma padrão cometidos pelos alunos, tampouco o que foi escrito servirá apenas para gerar uma nota. O professor será, portanto, leitor, um leitor que vai ao texto para saber o que ele tem a dizer. Evidentemente, o professor avaliará a produção, pois precisa intervir como aquele que é mais experiente com o trabalho com a escrita, porém, essa avaliação se dará de modo a convidar o aluno a olhar cuidadosamente para sua escrita e entendê-la como um processo que exige o retorno ao texto para reescrevê-lo.

Para esse movimento de retomada, a análise linguística é fundamental, pois, por meio dela, é possível refletir sobre o funcionamento da língua. Isto é, concebe-se que apesar da sua organização, regras e sistematização, a língua é viva e não é externa ao sujeito, por isso, nos textos, o aluno agenciará os recursos linguísticos disponíveis para se enunciar, considerando as convenções da linguagem.

Movida por essa discussão, proponho na seção a seguir a análise de algumas atividades que envolveram a leitura e a escrita desenvolvidas ao longo do ano de 2017 numa turma de terceiro ano do Ensino Fundamental de uma escola municipal de São José/SC.

\section{REDAÇÃO X PRODUÇÃO DE TEXTO: TÉCNICA X PROCESSO}

Na seção anterior discorri brevemente sobre os eixos de leitura, escrita e análise linguística, os quais fazem parte do trabalho com educação linguística e ainda requerem debate a fim de repensar a formação docente e as práticas escolares. Agora, foco especificamente em exemplos de atividades que elucidam empiricamente o trabalho realizado com textos em sala de aula.

Entretanto, antes de adentrar nos exemplos e nas análises, que serão embasadas a partir dos autores que tenho citado neste artigo, é importante salientar que de modo algum o objetivo desta reflexão é deslegitimar ou desrespeitar o trabalho docente. Também não é simplesmente questionar as escolhas por meio de opiniões pessoais, o que proponho é um convite à discussão com vistas a adensar os temas já debatidos na área de ensino de linguagem e do papel formativo da escola.

Ademais, como tratei na seção anterior, do mesmo modo que a formação escolar apresenta fragilidades e precisa ser repensada, isso também ocorre com a formação docente, porque, em geral, os cursos de licenciatura ainda estão distantes de uma formação que estreite a relação entre a teoria e a prática. Além disso, outra questão que se coloca ao analisar a prática docente são as condições precárias de trabalho do 
REVISTA X, Curitiba, volume 14, n.6,p. 272-285, 2019.

professor, sem horas efetivamente destinadas ao planeamento, além de outros problemas enfrentados no cotidiano do sistema escolar.

Dito isso, apresento o contexto das atividades que serão aqui debatidas. Todas elas foram retiradas de um caderno específico para produção textual (cedido a mim pelo professor da turma), que foi utilizado desde a primeira semana de aula, no mês de fevereiro de 2017, até novembro do referido ano. Essas produções foram solicitadas pelo professor regente de uma turma de terceiro ano do Ensino Fundamental, o que corresponde ao final do ciclo de alfabetização, de uma escola pública municipal localizada em São José/SC.

Após esse preâmbulo, retomo a discussão da seção anterior sobre a escrita de textos na escola. Como citado, essa atividade está bastante assentada na ideia de escrita seguindo um modelo clássico de redação, que parte de um tema específico e que, em geral, exige a colocação de um título, o preenchimento de trinta linhas, a separação do texto em parágrafos e o domínio da norma padrão da língua. A esse tipo de proposta, Geraldi (1984) tece duras críticas.

O exercício de redação, na escola, tem sido um martírio não só para os alunos, mas também para os professores. Os temas propostos têm se repetido de ano para ano e os alunos logo percebem isso. Assim, podem guardar seus textos de um ano escolar para o outro para novamente entregá-los ao professor, na época oportuna: no início do ano, o título infalível "Minhas férias"; em maio, "O dia das mães"; em junho, "Festa junina"; e assim por diante... Tais temas, além de insípidos, são repetitivos todos os anos, de tal modo que as crianças passam a pensar que só escrevem sobre essas "coisas". (GERALDI, 1984, p. 64)

À época da formação do PNAIC, muitos cursistas questionaram a discussão desse tema, pois apontaram que esse exercício de redação já havia sido superado e não era mais realizado nas salas de aula, visto que os docentes realizam um trabalho mais efetivo com os textos materializados nos gêneros do discurso. No entanto, como podemos observar na Figura 1 abaixo, essa prática ainda é comum. 
REVISTA X, Curitiba, volume 14, n.6,p. 272-285, 2019.

Figura 1 - Primeira redação

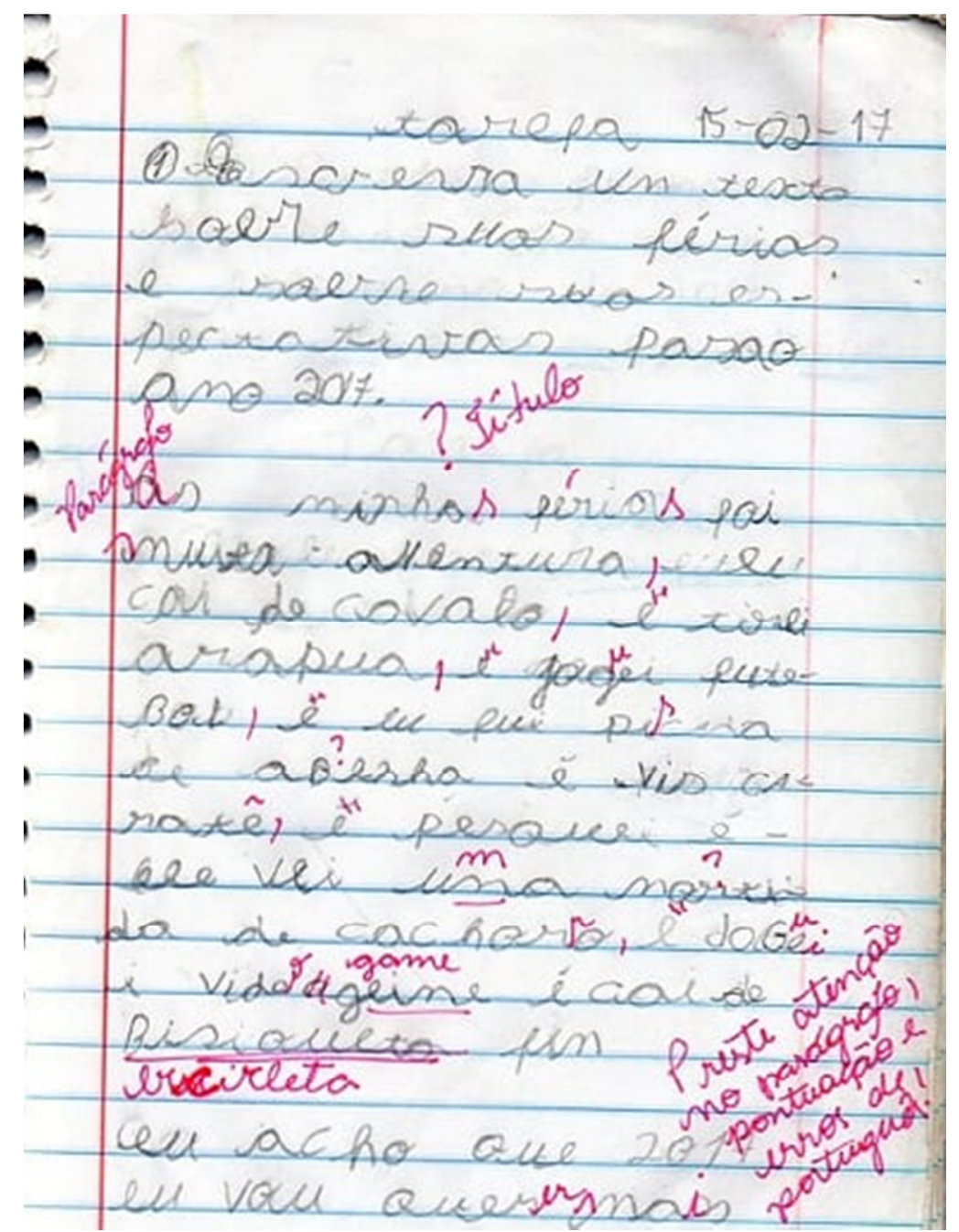

Fonte: elaborada pela autora

De acordo com a Figura 1, ao iniciar o ano letivo de 2017, o docente solicitou que a turma realizasse uma produção escrita com o tema: férias e expectativas para o ano. Esta prática é recorrente nos anos iniciais e nas aulas e é chamada de escrita espontânea. Ela visa dar subsídios para o diagnóstico do grupo, como escrevem, quais as recorrências e problemas em relação à norma da língua, que tipo de conhecimentos expõem etc.

Além disso, possivelmente, outro objetivo do professor era conhecer os alunos e saber o que fizeram no recesso escolar, o que parece bastante válido, bem como saber suas expectativas para o ano, o que poderia, inclusive, auxiliar no próprio planejamento de atividades futuras. 
REVISTA X, Curitiba, volume 14, n.6,p. 272-285, 2019.

Entretanto, ao analisar a correção do texto, depreende-se que a avaliação foi realizada com base no apontamento dos "erros" cometidos pelo aluno, no geral, na grafia das palavras, além de outras regras de convenção. Sobre isso, é importante salientar que esses apontamentos devem ser feitos, porém, o que parece problemático é o modo como o docente incide no texto do aluno, num texto que não é dele e que, por isso, exige maior cuidado, até mesmo para que não se perca a compreensão da função social da escrita.

Ademais, ao ler a indicação da atividade: "escreva um texto sobre suas férias e sobre suas expectativas para 2017”, percebe-se que as orientações são bastante genéricas, sem especificação do que se espera desse texto ou os descritores para sua leitura e avaliação. Além disso, não é solicitado que o aluno produza esse texto materializado em um gênero específico, o que impede, desse modo, que características de seu formato sejam requeridas. Assim como não há nada que toque sob a necessidade de colocação do título, portanto, ele não pode ser cobrado como uma regra, porque há textos que não têm título e que circulam socialmente.

Essa atividade, então, corrobora com as discussões acerca da produção de textos na escola, pois,

normalmente, nos exercícios e nas provas de redação, a linguagem deixa de cumprir qualquer função real, construindo-se uma situação artificial, na qual o estudante, à revelia de sua vontade, é obrigado a escrever sobre um assunto em que não havia pensado antes, no momento em que não se propôs e, acima de tudo, tendo que demonstrar que sabe. E sabe o quê? Escrever. Além disso, que esteja claro que ele está sendo julgado, testado [...]. (GERALDI, 1984, p. 126)

Outra questão em relação à correção é o lugar que o professor ocupa no processo, não como aquele que lê com o objetivo de se encontrar com o aluno por meio do texto, e sim, apenas como aquele que marca os "erros". Assim, como aponta Britto (2003), a atividade de escrita perde seu sentido quando a produção se torna apenas um produto avaliativo que não é retomada após receber a nota dada pelo professor.

Observa-se ainda a falta de continuidade no processo de escrita, porque não foi solicitada a refacção textual. Uma vez que, no caderno de produção, a tarefa subsequente a essa foi a escrita de outro texto, com a seguinte indicação: "conte uma história de carnaval”. Assim, a possível proposta de utilizar a escrita para subsidiar o planejamento do professor também se perde, visto que essa atividade não gerou uma 
REVISTA X, Curitiba, volume 14, n.6,p. 272-285, 2019.

reflexão para modificar as ações subsequentes à escrita sobre as férias e as expectativas para o ano.

Por isso, a importância de compreender a concepção e a função do planejamento, como afirma Libâneo (1990):

O planejamento escolar é uma tarefa docente que inclui tanto a previsão das atividades didáticas em termos da sua organização e coordenação em face de objetivos propostos, quanto a sua revisão e adequação ao decorrer do plano de ensino. O planejamento é um meio para se programar as ações docentes, mas é também um momento de pesquisa e reflexão intimamente ligado à avaliação. (LIBÂNEO, 1990, p. 221)

Para dar continuidade à discussão, trago o exemplo da última produção escrita do ano, realizada no final do mês de novembro de 2017, na Figura 2 a seguir.

Figura 2 - Última redação

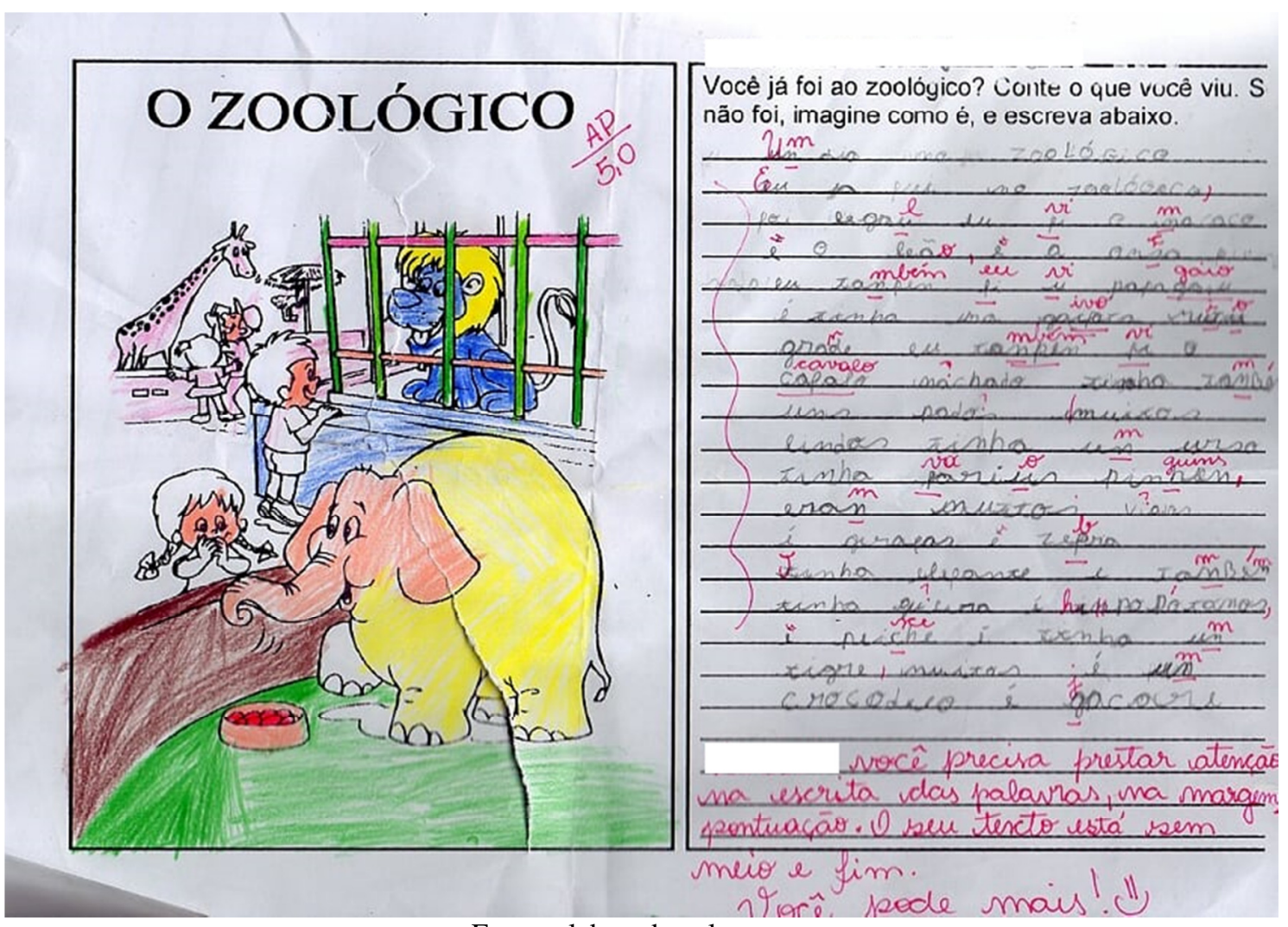

Fonte: elaborada pela autora

Nesse exemplo, o professor buscou referências na internet, em bancos de dados de atividades disponibilizadas no Google, e selecionou uma proposta que, além de envolver a escrita, traz uma ilustração para ser colorida pelos alunos. Assim, ao observar a imagem, já é possível inferir que ela não foi criada pelo professor, tanto a indicação para a escrita quanto a ilustração estavam prontas. 
REVISTA X, Curitiba, volume 14, n.6,p. 272-285, 2019.

Nesse sentido, ao analisar a indicação para escrita, há uma questão bastante significativa, pois os alunos não foram ao zoológico em uma saída de campo da escola, por isso não é possível prever que todos já tivessem essa experiência; para resolver esse impasse, a recomendação sugere que os alunos que não foram ao zoológico imaginem como esse lugar é. No entanto, isso é incoerente, pois a proposta era justamente escrever a partir de uma vivência, o que torna a escrita inviável quando o aluno não tem essa vivência.

Assim sendo, há um descolamento da proposta de escrita e a efetiva produção de textos reais, pois um texto em forma de relato de experiência só faz sentido para que o aluno possa relatar aquilo que viveu, o que encontrou no zoológico, que animais viu, que conhecimentos aprendeu etc. O que se difere, então, da redação solicitada na Figura 2.

Quanto a correção realizada pelo professor, nota-se apontamentos bastante semelhantes aos que foram feitos na primeira escrita, porém, essa atividade corresponde à última escrita, ou seja, não houve um avanço significativo em relação ao processo de reflexão do aluno sobre o próprio texto, porque mais uma vez ele recebe a sinalização dos "erros", porém, ele não é convidado a pensar sobre o seu texto e reescrevê-lo.

O professor faz um movimento de diálogo com o aluno quando além de marcar as correções também deixa um recado ao final do texto. Porém, esse movimento ainda está distante de uma interlocução efetiva entre professor e aluno, com sugestões claras para repensar o texto. O que compromete a aprendizagem dos alunos, afinal, “[...] as crianças crescem e se desenvolvem em função das formas como estabelecem as relações de interação com o outro humano; sabemos também que, neste processo, ela se põe inteira e experimenta e utiliza toda a potência de seu corpo". (BRITTO, 2018, p. 21)

Além do que foi exposto em relação ao trabalho com a escrita, a Figura 2 conta com uma ilustração para o aluno pintar. Ao analisá-la, nota-se a artificialidade com a qual os animais são apresentados no contexto infantil, tema bastante debatido por Britto (2012), que afirma que esse tipo de atividade

Tende à banalização dos valores e conteúdos; é curioso ver como o zoológico da literatura infantil tem todos os animais sem ter nenhum, a exemplo do que acontece com os desenhos animados. Bicho não é bicho, são todos de pelúcia, de plástico, bonequinhos: ursinhos, girafinhas, cachorrinhos, joaninhas, elefantezinhos, monstrinhos. Hipocritamente humanizados, os bichos das histórias dessa literatura perdem sua natureza e habitam um mundo artificial e superficial. (BRITTO, 2012, p. 113) 
REVISTA X, Curitiba, volume 14, n.6,p. 272-285, 2019.

De nenhum modo o autor diz que o trabalho com a criatividade e com a ludicidade não deva ser realizado na escola, principalmente, com as crianças, entretanto, trazer desenhos, ilustrações, bonecos, entre outros para sala de aula não impede que esse trabalho seja baseado nas representações reais que esses materiais carregam, pois, conforme Britto (2012), o estímulo a essas fantasias controladas e padronizadas banalizam o processo de produção artística e o próprio desenvolvimento da humanidade, pois não assumem um compromisso efetivo de transcender ao cotidiano imediato e alienado imposto pela sociedade capitalista.

\section{CONCLUSÃO}

Após a exposição teórica e a análise nas seções anteriores, reitero que o objetivo deste artigo foi propor um debate, subsidiado por autores da área de ensino da linguagem, sobre as práticas com os textos escritos em sala de aula. O propósito deste trabalho foi, portanto, contribuir para a reflexão dos profissionais da área, convidandoos a reverem ações que estão cristalizadas nas escolas e que podem ser modificadas a partir do adensamento da compreensão das teorias que esteiam a prática docente.

Portanto, ao levar o texto para sala de aula, é fundamental a clareza sobre a função social que esse texto ocupa para que ele não se torne um objeto trabalhado artificialmente. Para isso, o docente precisa ter no horizonte os encaminhamentos metodológicos para orientar as atividades de leitura e de escrita, o que inclui lidar com as especificidades da língua e da produção escrita para assim não focar apenas na forma, sem se ocupar com o conteúdo do texto; não realizar correções genéricas apontando só os "erros"; trabalhar mais verticalmente a análise do texto e reescrita, o que exige continuidade da atividade; e não tratar o texto somente como instrumento avaliativo.

Essas reflexões fazem parte constante do agir docente uma vez que o papel da escola, enquanto instituição legitimada socialmente para transmissão dos conhecimentos produzidos ao longo da história da humanidade, é assegurar que os alunos tenham acesso à escrita e aos discursos produzidos por meio dela. Para isso, o ensino da escrita e das suas especificidades exige um exercício sistemático e reflexivo, comprometido com uma formação emancipadora, e não alienadora.

\section{REFERÊNCIAS}

BRITO, Luiz Percival Leme. Contra o consenso - cultura escrita, educação e participação. 1. ed. Campinas: Mercado de Letras, 2003. 
REVISTA X, Curitiba, volume 14, n.6,p. 272-285, 2019.

Letras, 2012.

Inquietudes e desacordos: a leitura além do óbvio. Campinas, SP: Mercado de Ler com crianças. Revista Exitus, v. 8, p. 17-31, 2018.

FRANCO, Ângela. Metodologia de ensino: língua portuguesa. Belo Horizonte: Ed. Lê: Fundação Helena Antipoff, 1997.

GERALDI, João Wanderley (org.). O texto na sala de aula: leitura \& produção. Cascavel: Assoeste, 1984.

Portos de Passagem. São Paulo: Martins Fontes, 1991.

LIBÂNEO, José Carlos. Didática. São Paulo: Cortez, 1990.

MORTATTI, Maria Rosário Longo. Os sentidos da alfabetização. São Paulo: Ed. UNESP; CONPED, 2000.

SOARES, Magda. Letramento e alfabetização: as muitas facetas. Revista Brasileira de Educação. n. 25, p. 5-17, jan./abr. 2004. 